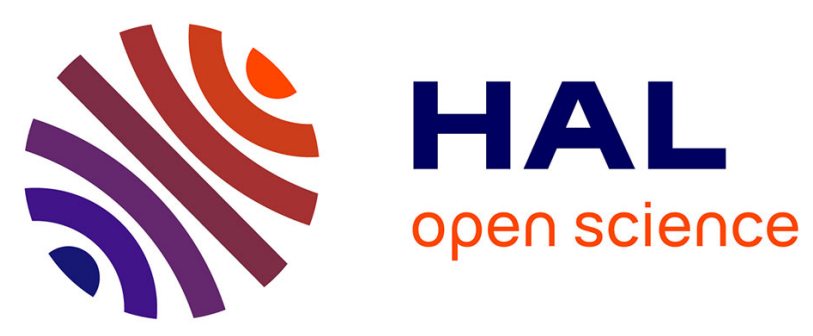

\title{
Cementless total hip arthroplasty in patients with rheumatoid arthritis using a tapered designed titanium hip stem minimum: 10-year results
}

Hans D. Carl, Jan Ploetzner, Bernd Swoboda, Gerd Weseloh, Lutz Arne Mueller

\section{To cite this version:}

Hans D. Carl, Jan Ploetzner, Bernd Swoboda, Gerd Weseloh, Lutz Arne Mueller. Cementless total hip arthroplasty in patients with rheumatoid arthritis using a tapered designed titanium hip stem minimum: 10-year results. Rheumatology International, 2009, 31 (3), pp.353-359. 10.1007/s00296009-1300-1 . hal-00568317

\section{HAL Id: hal-00568317 https://hal.science/hal-00568317}

Submitted on 23 Feb 2011

HAL is a multi-disciplinary open access archive for the deposit and dissemination of scientific research documents, whether they are published or not. The documents may come from teaching and research institutions in France or abroad, or from public or private research centers.
L'archive ouverte pluridisciplinaire HAL, est destinée au dépôt et à la diffusion de documents scientifiques de niveau recherche, publiés ou non, émanant des établissements d'enseignement et de recherche français ou étrangers, des laboratoires publics ou privés. 


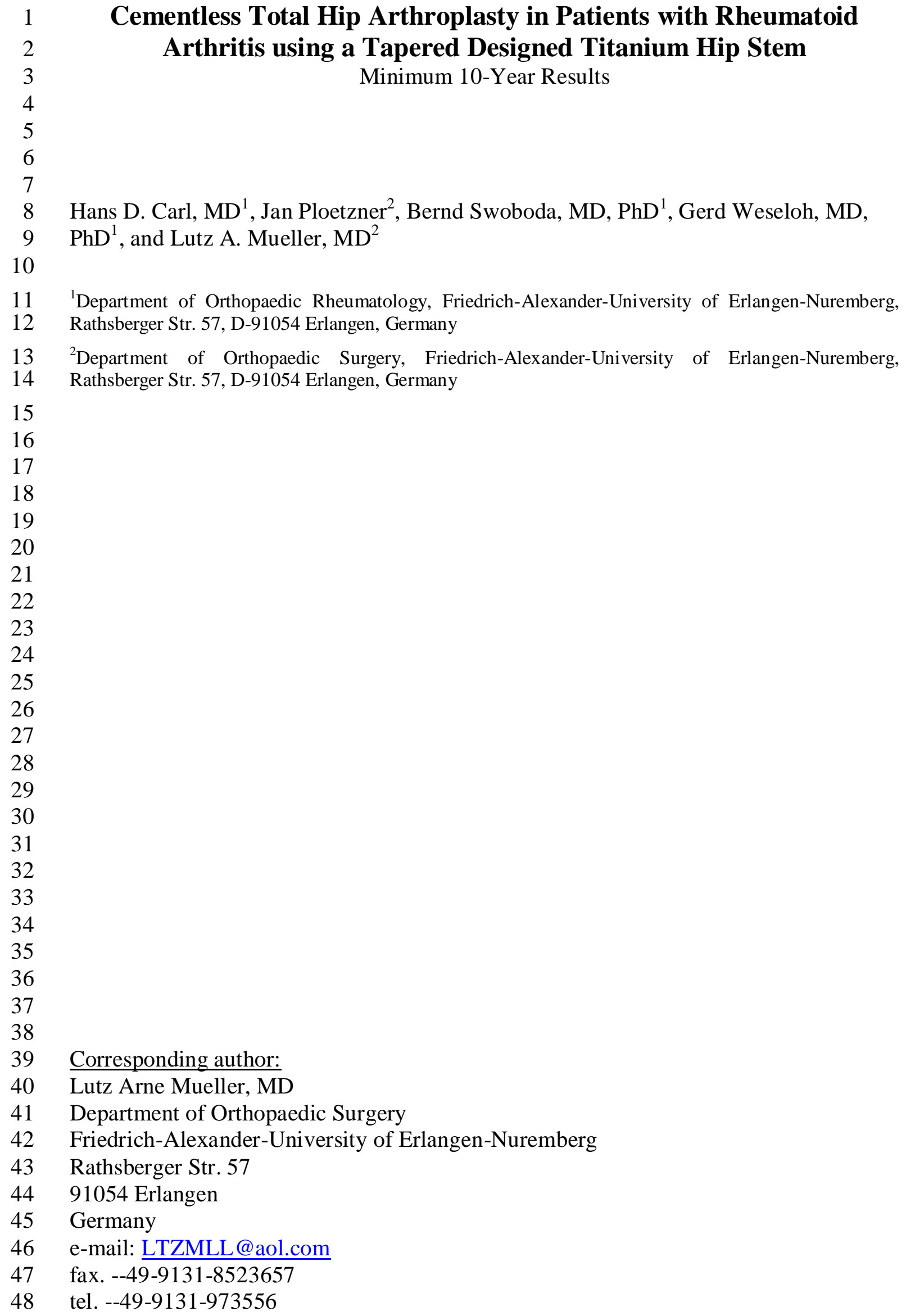

39 Corresponding author:

40 Lutz Arne Mueller, MD

41 Department of Orthopaedic Surgery

42 Friedrich-Alexander-University of Erlangen-Nuremberg

43 Rathsberger Str. 57

4491054 Erlangen

45 Germany

46 e-mail: LTZMLL@aol.com

47 fax. --49-9131-8523657

48 tel. --49-9131-973556 


\section{Abstract}

52 The results of a cementless tapered designed femoral stem was studied at a minimum 10 53 year follow-up in a non-selected, consecutive group of 27 patients (39 hips) with 54 rheumatoid arthritis. Clinical and radiological analyses were performed in 27 hips, 17 55 patients (mean age at surgery 45 years) after a mean of 12 years. Using the Harris Hip 56 Score, 14 hips were rated as excellent; 9, good; 2, fair; and 2, poor. No stem had to be 57 revised for aseptic loosening. Proximal stress shielding was observed in 26 hips (96\%), 58 heterotopic ossification was present in 11 hips (41\%). 6 hips required revision of the 59 acetabular component. With uncemented tapered femoral fixation excellent 12 year

60 results are achieved in patients with rheumatoid arthritis.

61

62

63

64

65

66

67

68

69

70

71 


\section{Introduction}

75 The total number of rheumatoid arthritis (RA) patients in total hip arthroplasty (THA) databases ranges from $3 \%(61,568$ THA patients) in a United States cohort to $6 \%$

77 (93,852 THA patients) in the Swedish National Registry [1,2]. A multidisciplinary approach is required for the management of these patients, with surgical procedures preferably undertaken by orthopaedic surgeons who are familiar with the specific

80 problems of RA patients. While THA in patients with RA is known to greatly improve functional abilitiy and thus self-support of the patient [3], controvorsy remains among orthropaedic surgeons concerning the optimal fixation of the implant [4-19].

Cemented THA has traditionally been considered the gold standard for the treatment of

84 patients with RA as poor bone stock caused by generalized disease activity, immobility and steroid therapy was thought to undermine primary stability and bony ingrowth of cementless implants [4,6].

Several studies have shown higher rates of loosening of cemented femoral components in patients with RA compared with cemented THA in patients with osteoarthritis (OA) $[5,15]$. The Finish arthroplasty register found that the risk of stem revision due to aseptic loosening for patients with RA under the age of 55 (2557 primary THA) was

91 higher with cemented stems than with proximaly porous coated uncemented stems [7].

92 Femoral failure rates of $5.3 \%$ and $8 \%$ after an average follow-up of 7.4 to 4.3 years

93 have been reported with cemented THA for patients with RA [16,17].

943 long-term follow-up series with a single uncemented contemporary femoral 95 component in patients with RA have been published. The results have been promesing 96 with revision rates between $0 \%$ and $1 \%$ after a mean follow-up of 8 to 10 years $97[9,10,14]$. 
98 We have retrospectively assesed the long-term clinical and radiological results (mean time of follow-up: 12,2 years; minimum 10 years) of a non-selected, consecutive series

100 for patients with RA who all underwent cementless THA with the femoral component

101 cementless system (CLS, Sulzer Medica, CH; now: Zimmer, Warsaw, Indiana, USA), in

102 combination with one of five different actabular components.

\section{Patients and Methods}

105 We performed 39 consecutive, unselected primary THA in patients with adult-onset RA using the CLS stem on 27 patients. All patients fullfilled the diagnostic criteria of the

107 American College of Rheumatology. For the follow-up analysis after a mean time of 12,2 years (minimum 10 years) there were 11 women (18 hips) and 6 men (9 hips) with 109 an average age of 45,3 years (26 to 56) at time of surgery. 5 patients (5 hips) were lost

110 to follow-up and 5 patients (7 hips) had died prior to follow-up investigation. Prior to 111 surgery 5 patients ( 8 hips) had been taking oral corticosteroids only, 3 patients ( 6 hips) 112 took oral steroids and at least one disease modifying rheumatic drug such as 113 methotrexate, 9 patients (12 hips) had no medication at time of the index operation. No

114 patient had received bone modulating drugs during the entire period of follow-up. There

115 were 4 patients (4 hips) rated as Charnely A, 1 patient (2 hips) as Charnely B and 12 116 patients (21 hips) as Charnely C [20].

117 The CLS femoral component is a collarless, three-dimensional tapered wedged made of 118 titanium alloy $\left(\mathrm{Ti}_{6} \mathrm{Al}_{7} \mathrm{Nb}\right)$. Ribs in the proximal part of the prothesis are designed to 119 minimize rotational migration. The distal part is intentionally made small to avoid 120 filling of the intramedullary canal in the diaphysis in order to encourage proximal load 121 transfer to the femur. The surface was rough blasted and had no porous coating [21]. All procedures were performed in staged settings by three different senior surgeon in a 
123 closed air enclosure with laminar air flow. All patients were placed in supine position

124 and operated on with a direct transgluteal lateral Bauer approach [22]. The largest stem

125 that provided a stable press-fit was inserted after preparation of the femoral canal with

126 chipped-tooth broaches.

127 Depending on availability and the surgeons preference one of four different cementless

128 press-fit acetabular components were used. There were 7 Fitek cups with a metasul

129 polyethylen (PE) liner (Zimmer, Warsaw, USA; before: Sulzer Medica, Wintherthur,

130 Switzerland) 6 of which were fitted with screws; 9 hydroxlapatit-coated and 4

131 zirconium-coated Phönix cups (Brehm, Weisendorf, Germany) fitted with PE-liners

132 (Brehm, Weisendorf, Germany) in 11 cases and alumina inlays in 2 cases (Biolox,

133 CermaTec, Plochingen, Germany) ; 1 Plasmacup (PE-inlay) fixed with screws

134 (Aesculap, Tuttlingen, Germany) and 1 Wagner cup (PE-inlay) (Zimmer, Warsaw,

135 USA; before: Sulzer Medica, Wintherthur, Switzerland). 5 acetabular components were

136 cemented: in 3 cases acetabular reconstruction was required and a Ganz reinforcement

137 ring (Zimmer, Warsaw, USA; before: Sulzer Medica, Wintherthur, Switzerland) was

138 implanted in addition to the cemented metasul PE-cup (Zimmer, Warsaw, USA; before:

139 Sulzer Medica, Wintherthur, Switzerland) and in 2 cases cemented PE-cups (Brehm,

140 Wesiendorf, Germany) were used without acetabular reconstruction.

141 The femroal head size was $28 \mathrm{~mm}$ in 20 hips and $32 \mathrm{~mm}$ in 7 hips, there were 16

142 alumina ceramic (Biolox, CermaTec, Plochingen, Germany) and 11 CoCrMo-alloy

143 (Metasul, Protek GmbH, Munich, Germany) heads. Due to the wide variety of

144 acetabular implants used their performance was not the major target of this 145 investigation.

146 All patients received prophylaxis for heterotopic ossification by oral administration of 3

147 doses of 50mg diclofenac for 2 weeks postoperativley. Routinely patients were given 
148 perioperative antibiotics (single shot of $2 \mathrm{~g}$ Cefazolin i.v.) and thromboembolism

149 prophylaxis with subcutaneous heparin. Postoperatively, touch weight-bearing up to 15

$150 \mathrm{~kg}$ was allowed for the first 6 weeks, then progressively increased loading to full

151 weight-bearing within the next 2 weeks. At the final follow-up all patients were assesed

152 clinically using the Harris hip score [23]. Preoperative pain, range of motion and

153 function were reconstructed retrospectively by interview and patients charts.

154 Radiographs were evaluated by an independent observer (LAM) who was unaware of 155 the clinical outcome of the surgical procedure. Evaluation of the femoral and actabular 156 components was performed using published criteria [24]. Radiological "stability" of the

157 femoral component was additionally assessed according to the criteria of Engh et al.

158 [25]. Location of radiolucent lines, osteolysis and cortical hypertrophy were rated 159 according to the Gruen criteria [26]. For evaluation of heterotopic ossification, the 160 Brooker classification was used [27]. Stress shielding was classified as grade I when 161 only resorption of the medial edge of the resection line appeared, grade II meant 162 additional proximal medial bone resorption, while grade III findings extended more 163 distally [28,29].

\section{Results}

166 Of the 27 patients (39 hips) in this study, 5 patients ( 7 hips) had deceased at the time of 167 the follow-up. Intermediate clincal and radiological follow up of 3 patients (5 hips) 168 ranging from 5 to 8 years of the deceased patients showed radiological signs of stable 169 ingrowth of all stems without impending failures. There were 2 patients ( 2 hips) who 170 had died with their hips intact but no clinical or radiological data beyond the 1 -year 171 follow-up at which time the implant was functioning well. 5 patients (5 hips) were lost 
172 to follow-up, only a 2 month postoperative clinical and radiological follow-up was

173 available with a well functioning hip (fig.1).

174 Thus, clincal and radiological data were available of 17 patients (27 hips) after a mean

175 of 12,2 years follow-up (minimum 10 years). There were 10 women (18 hips) and 7

176 men (9 hips) with an average age at surgery of 45,3 years (26 to 55). Of the 27 implants

177 directly accounted for, no femoral component was revised and all stems had bony

178 ingrowth. 5 cups (19\%) had to be revised due to aseptic loosening, for one additional

179 cup the liner had to be changed due to extensive wear (table 1).

180 The Harris Hip Score (HHS) was not taken preoperatively. Retrospective assessment of

181 patient charts showed marked pain in all patients. Range of hip motion was limited to

182 less than $110^{\circ}$ in all cases, only 6 patients $(35 \%)$ were able to walk without a cane or

183 crutches. At follow-up the average HHS was 86. 14 hips were rated as excellent (52\%);

184 9, good (33\%); and 4, fair (14\%). 25 hips (93\%) had total relief from pain in the thigh,

185 groin or buttocks. 2 hips $(7 \%)$ presented with occasional pain of the buttocks and the

186 and the tigh. A Trendelenburg limp was found in 1 hip (4\%) caused by a postoperative

187 partial paralysis of the sciatic nerve after acetabular revision surgery. 13 patients (76\%)

188 could walk over 500 meters, 4 patients (24\%) walked outdoors under 500 meters. 11

189 patients $(65 \%)$ needed no assistive devices for walking while 2 patients (12\%) used a

190 cane for outdoor walking only, 3 patients (18\%) regularly used one cane.

191 No stem had to be revised for aseptic loosening and all stems presented complete bony

192 ingrowth with no signs of definite or probable loosening. No postoperative subsidence

193 was seen. 5 stems were undersized, 4 in slight varus and 2 in minimal valgus position.

194 Proximal stress shielding was observed in all hips. Bone resorption in the proximal

195 portion of the femur (Gruen zones 1 and 7), which was interpreted as grade II stress

196 shielding, was present in 26 hips (96\%), in one cases stress-shielding extended to Gruen 
197 zones 2 and 6 (grade III). A non progressive $4 \times 5 \times 5 \mathrm{~mm}$ osteolysis was seen in 1 patient

198 (1 hip) located in Gruen zone 7, with 1-2mm wear of the cemented PE-cup. In another

199 case of suspected press-fit cup loosening both stem and cup were intraoperatively found

200 to be stable, a small proximal osteolysis in Gruen zone 7 was filled with autologous

201 bone graft.

202 Radiolucencies of the stem without progression were found in 3 cases, all of which were

203 located in the proximal gruen zones I. Cortical hypertrophy was seen in 3 hips (11\%) in

204 Gruen zone 3 and 5. 12 hips $45 \%$ developed a radiographic appearance of bone

205 apposition at the tip of the stem. Heterotopic ossification was present in 11 hips (41\%):

2068 hips (30\%) grade I and 3 hips (11\%) grade II.

207 With uncemented tapered femoral fixation excellent 12 year results are achieved in 208 patients with rheumatoid arthritis (figure 2).

209 Acetabular component. For 22 acetabular components (81\%) fixation was good 210 without change in position. 5 cups (19\%; 4 press-fit zirconium-coated Phoenix cups and

211 one cemented PE-cup; Brehm, Weisendorf, Germany) had to be revised due to aseptic

212 loosening, for one additional cup the liner had to be changed due to extensive wear

213 (table. 1). Of the 22 non-revised acetabular components none showed signs of osteolysis

214 and radiolucencies were seen in 1 hip (4\%) in Zone II and III.

215 The amount of wear of the polyethylene liner or cup ( $n=20$ of the 22 non-revised hips)

216 was analyzed in increments of $1 \mathrm{~mm}$ maximum accuracy: < $1 \mathrm{~mm}(1 \mathrm{hip}, 4 \%), 1-2 \mathrm{~mm}$

217 (7 hips, $26 \%, 4$ PE-liners, 3 metasul-PE-liners).

218 The 6 hips which required isolated revision of the cup had radiographically bone219 ingrown femoral components that were stable on examination during the operation. The 220 radiological follow-up showed that these stems remained radiologically bone-ingrown. 
221 We observed no deep vein thrombosis, no luxation and no periprosthetic fracture in our 222 cohort.

\section{Discussion}

225 In our non-selected, consecutive series of patients with RA who all underwent cementless THA the survival of the tapered designed stem has been excellent. No stem had to be revised and all showed signs of stable ingrowth after a mean follow-up of 12,2 years (minimum 10 years). Aseptic cup loosening was seen in four cases which had to

229 be revised, additionally one liner had to be replaced due to extensive wear. Durable 230 acetabular fixations remains to be the major problem compromising the longevity of cementless THA for patients with RA.

232 The greater incidence of actabular and femoral loosening after cemented THA for 233 patients with RA compared to those with OA $[5,12,15,17,18,30]$ has been attributed to 234 periactabular and generalized osteoporosis related to disease activity, steroid therapy 235 and immobility [6,31,32]. As for elderly patients with OA, the hypothised poorer bone stock of patients with RA has been the main arguement for cemented THA.

237 The increasing number of investigations with promesing results for cementless THA for 238 patients with RA $[4,8-11,13]$ has recently been confirmed by a study of the Finnish 239 Arthroplasty Register for the femoral component, while for the acetabulum cemented 240 all-polyethylene cups were the implant of choice [7] (table 2).

241 Three long-term follow-up series with a single uncemented contemporary femoral 242 component in patients with RA have been published: Lyback et al. [4] reported an 243 excellent 100\% 10-year survival rate (with aseptic loosening as an endpoint) for a group 244 of 55 patients (77 hips) with juvenile chronic arthritis (mean age at operation 28 years) 
245 who had received the proximally circumferentially porous-coated Bi-metric stem. For 246 another proximally circumferentially porous-coated uncemented stem (Biomet

247 Taperloc) Keisu et al [10] reported no revision and no signs of radiological loosening 248 after a mean follow-up of 8 years in group of 39 patients (50 hips) with adult-onset RA 249 (mean age at operation 55 years). Jana et al [9] reported of 55 patients (71 hips) with 250 adult-onset RA (mean age at operation 55.1 years) after a mean follow-up of 11.2 years with 1 stem revised and an additional 4 stems showing radiological signs of loosening (porous-coated Anatomic Medullary Locking stem).

253 It is well published, that for patients with OA of the hip joint, tapered designed 254 uncemented stems achieve excellent clinical and radiological results at 10 years 255 postoperatively [33-35]. Specifically with the CLS stem used in the present patient 256 cohort, we have observed similar excellent results for 94 patients (107 hips) with OA 257 (mean age at operation 51 years) after a mean follow-up of 10.3 years, no stem had to 258 be revised and radiological stable ingrowth was observed in $95 \%$ of the radiographically 259 analysed cases [35].

260 Our single femoral implant, single surgeon series is the first with a mean 12,2 year 261 (minium 10 years) follow-up for tapered designed uncemented stems in patients with 262 RA and only the second publication thus far with an above mean 10-year-results for uncemented stems of patients with adult-onset RA. We recognize that our study is

264 limited by the relatively small patient cohort and the retrospective nature of our 265 investigation. Furthermore our series is nonrandomised, thus no direct comparisons with 266 a cemented group is possible. Nevertheless, we managed to account for all but 5 of the 267 patients still alive of this series. Even though no match of the presented RA group was 268 possible with an osteoarthritic control group, the number of stem revisions and stable 
radiological ingrowth with the same implant show equally excellent results for both groups in our hospital [35].

271 All published short- and longterm data with a single contemporary uncemented femoral component for patients with juvenile and adult-onset RA confirm the encouraring results of our series $[4,8-11,13]$ underlined by the report of the Finnish Arthroplasty

274 Register [7] who analysed 2,557 THA for RA in younger patients and found favourable 275 results for uncemented femoral implants.

276 The chronic course of RA with multiple affected joints of the lower limbs affected, 277 makes the clinical evaluation of a specific surgical procedure difficult to interpret. 278 While excellent clincal results after THA were reported by Keisu et al. [10] with a 279 relatively high HHS of 93 (follow-up mean: 8 years; mean age at operation: 55 years) 280 and $32 \%$ of their patients classified according to Charnley as grade C, Jana et al. [9] 281 found the Merle D'Aubigné and Postel walking score (follow-up mean: 10 years; mean 282 age at operation: 55.1 years) to improve in only $61 \%$ of their patients, $20 \%$ had lower scores. Even though 12 patients (21 hips, 78\%) of our patients were rated as Charnely C 284 we found satisfying clincal results with an average HHS of 86 at follow-up. All patients 285 reported clinical improvement with reduced pain and increased walking distance.

286 Keisu et al. [10] noted postoperative mild thigh pain in only $2,2 \%$ of his RA patients 287 after cementless THA with the titanium alloy, circumferntial plasma spray coated, 288 Taperloc femoral stem. Accordingly, we observed 2 patients who presented with 289 occasional thigh pain. With the same implant in the same clinic and a comparable mean 290 follow-up time thigh pain was observed only for patients with OA in cases of 291 radiologicaly loose, but not yet revised acetabular components. Whether the low incidence of thigh pain compared to other cementless implants [36,37] is due to the 
tapered geometry that is believed to distribute stress over a larger area remains 294 speculative [10, 38].

295 No case of superficial or deep wound infection was seen in our series. While for all 296 patients who had taken oral coritcosteroids preoperatively the dose was increased 297 perioperatively and administered intravenously to avoid an addison-crisis, other 298 immunosuppressing drugs such as MTX were paused 2 weeks prior to surgery until 299 definite wound healing (2 weeks postoperatively) was reached. No clear consensus 300 exists on whether methotrexate (MTX) should be continued or whether this therapy 301 should be discontinued for a few weeks in patients with rheumatoid arthritis (RA) 302 undergoing surgery. Pieringer et al. [39] analysed the current literature according to 303 which continued MTX therapy appears to be safe perioperatively and seems also to be 304 associated with a reduced risk of flares, even though none of examined papers addressed 305 the issue of safety in connection with comorbidities. Our series is to small to make any conclusion on the observed rate of infection and the influence of discontinuing MTX

307 therapie perioperatively.

308 Radiographic evidence of bone ingrowth of the stem in our series (100\%) is equal to 309 the radiographic results of Keisu et al. [10] (100\% radiographic evidence of bone 310 ingrowth). Despite reported an increased polyethylene wear rate Keisu et al. [10] 311 observed no case of proxmal or distal femoral osteolysis. They believed that the 312 circumferntial plasma spray coating in combination with the $100 \%$ rate of proximal 313 bone ingrowth of the Taperloc titanium alloy femoral stem protected the femoral canal 314 from PE-debris and thus osteolysis [10].

315 Despite polyethylen particulate debris, osteolysis and radiolucencies were never of 316 clinical or radiological significance for the femoral component in our investigation.

317 Schramm et al [35] reported wear of the polyethylene liners of $<1 \mathrm{~mm}(56 \%), 1-2 \mathrm{~mm}$ 
318 (29\%), > $2 \mathrm{~mm}(5 \%)$, for patients with osteoarthritis of the hip joint (mean time of

319 follow-up 10.3 years, mean age at operation 51 years) who had received the same 320 prosthesis in the same clinic with an identical polyethylen liner. Even though our cohort 321 was slightly younger and our mean follow-up an average 2 years longer, we observed 322 less PE-wear (< $1 \mathrm{~mm}$ (1 hip, 4\%), 1-2 mm (7 hips, $26 \%, 4$ PE-liners, 3 metasul-PE323 liners) which be contribute to the lower physical demand of RA patients.

324 Even though acetabular components were not the major target of this investigation due 325 to the wide variety of acetabular implants used, their perfomance was considered good.

326 The 4 revised press-fit cups were all zirconium coated and prone for asepting loosening 327 caused by debonding of the zirconium from the cup. None of the non-circonium coated 328 press-fit cups had to be revised or showed radiological signs of loosening at follow-up.

329 The results of cementless THA for young patients with rheumatoid arthritis are very 330 promising and comparable to patients with OA. Durable femoral and actabular fixation was achieved. Slight undersizing, varus and valgus positioning of the stem did not undermine good clinical results after a mean 12,2 year follow-up

\section{Legends}

336 Figure 1 Kaplan Meier curve indicating the lost to follow-up and a worst case (lost to follow-up and deceased patients) scenario.

Figure 245 year old male, 14 year follow-up. CLS-stem with Fitek press-fit cup. Stress-shielding in Gruen zones I and VII. 


\section{References}

343

3441 Mahomed NN, Barrett JA, Katz JN (2003) Rates and outcomes of primary and 345 revision total hip replacement in the United States Medicare Population. J Bone $346 \quad$ Joint Surg Am 85:27

3482 Malchau H, Herberts P, Ahnfelt L (1993) Prognosis of total hip replacement in 349 Sweden: follow-up of 92675 operations performed 1978-1990. Acta Orthop Scand 64:497

3523 Nelissen RGHH (2003) The impact of total joint replacement in rheumatoid arthritis. Prac Res Clin Rheum 17(5):831

4 Akesson K, Onsten I, Obrant KJ (1994) Periarticular bone in rheumatoid arthritis versus arthrosis. Histomorphometry in 103 hip biopsies. Acta Orthop Scand

358 65(2): 135

3636 Dequeker J, Maenaut K, Verwilghen J, et al. (1995) Osteoporosis in rheumatoid arthritis. Clin Exp Rheumatol 13(Suppl 12):21

Chmell MJ, Scott RD, Thomas WH, et al. (1997) Total hip arthroplasty with cement for juvenile rheumatoid arthritis. Results at a minimum of ten years in patients less than thirty years old. J Bone Joint Surg Am 79(1):44

3708 Garcia C, Fernandez J, Tonino A (1998) Rheumatoid arthritis and hydroxyapatite-coated hip prostheses: Five-year results. International ABG Study Group. J Arthroplasty (13)6:660 
3739 Jana AK, Engh CA Jr, Lewandowski PJ, et al. (2001) Total hip arthroplasty

374 using porous-coated femoral components in patients with rheumatoid arthritis. $\mathbf{J}$ Bone Joint Surg Br 83(5):686

376

$37710 \quad$ Keisu KS, Orozco F, McCallum JD et al. (2001) Cementless femoral fixation in 378 the rheumatoid patient undergoing total hip arthroplasty: minimum 5-year

379 results. J Arthroplasty 16(4):415

380

38111 Lachiewicz PF (1994) Porous-coated total hip arthroplasty in rheumatoid 382 arthritis. J Arthroplasty 9(1):9

38412 Lachiewicz PF, McCaskill B, Inglis A, et al. (1986) Total hip arthroplasty in 385 juvenile rheumatoid arthritis. Two to eleven-year results. J Bone Joint Surg Am

13 Loehr JF, Munzinger U, Tibesku C: Uncemented total hip arthroplasty in patients with rheumatoid arthritis. Clin Orthop Relat Res 366:31, 1999

14 Lybäck CC, Lybäck CO, Kyrö A, et al. (2004) Survival of Bi-Metric femoral stems in 77 total hip arthroplasties for juvenile chronic arthritis. Int Orthop

15 Poss R, Maloney JP, Ewald FC, et al. (1984) Six- to 11-year results of total hip arthroplasty in rheumatoid arthritis. Clin Orthop Relat Res 182:109 28(6):357

16 Ranawat CS, Dorr LD, Inglis AE (1980) Total hip arthroplasty in protrusio

17 Severt R, Wood R, Cracchiolo A 3rd, et al. (1991) Long-term follow-up of cemented total hip arthroplasty in rheumatoid arthritis. Clin Orthop Relat Res 265:137 rheumatoid arthritis. A long-term follow-up study. J Arthroplasty 2(3):191 
40719 Thomason HC, Lachiewicz PF (2001) The influence of technique on fixation of

$408 \quad$ primary total hip arthroplasty in patients with rheumatoid arthritis. J

$409 \quad$ Arthroplasty 16(5):628

410

41120 Charnley J (1972) The long-term results of low-friction arthroplasty of the hip 412 performed as a primary intervention. J Bone joint Surg Br 54:61

413

41421 Spotorno L, Romagnoli S, Ivaldo N, et al. (1993) The CLS system. Theoretical 415 concept and results. Acta Orthop Belg 59(Suppl 1):144

416

41722 Bauer R, Kerschbaumer F, Poisel S, et al. (1979) The transgluteal approach to 418 the hip joint. Arch Orthop Trauma Surg 1-2:47

419

42023 Harris WH (1969) Traumatic arthritis of the hip after dislocation and acetabular fractures: treatment by mold arthroplasty. An end-result study using a new

42424 Johnston RC, Fitzgerald RH, Jr., Harris WH, Poss R, Muller ME, Sledge CB 425 (1990) Clinical and radiographic evaluation of total hip replacement. A standard 427

42825 Engh CA, Bobyn JD, Glassman AH (1987) Porous-coated hip replacement. The 429 factors governing bone ingrowth, stress shielding, and clinical results. J Bone 431

43226 Gruen TA, McNiece GM, Amstutz HC (1979) Modes of failure of cemented stem-type femoral components: a radiographic analysis of loosening. Clin

43627 Brooker AE, Bowermann JW, Robinson RA, et al. (1973) Ectopic ossification 437 Orthop 141:17 following total hip replacement. Incidence and a method of classification. J Bone 439 
44028 Engh CA, McGovern TF, Bobyn JD, et al. (1992) A quantitative evaluation of 441 periprosthetic bone-remodeling after cementless total hip arthroplasty. J Bone Joint Surg Am 74(7):1009

443

44429 McLaughlin JR, Lee KR (1997) Total hip arthroplasty with an uncemented 445 femoral component. Excellent results at ten-year follow-up. J Bone Joint Surg Br 446 79(6):900

447

$44830 \quad$ Sarmiento A, Ebramzadeh E, Gogan WJ, et al. (1990) Total hip arthroplasty with cement. A long-term radiographic analysis in patients who are older than fifty and younger than fifty years. J Bone Joint Surg Am 72(10):1470

45231 Dequeker J, Geusens P (1990) Osteoporosis and arthritis. Ann Rheum Dis 49(5):276

32 Sambrook PN (2000) The skeleton in rheumatoid arthritis: common mechanisms for bone erosion and osteoporosis? J Rheumatol 27(11):2541

45833 Froimson MI, Garino J, Machenaud A, et al. (2007) Minimum 10-year Results of a Tapered, Titanium, Hydroxyapatite-Coated Hip Stem: An Independent

34 Reikerås O, Gunderson RB (2003) Excellent results of HA coating on a gritblasted stem: 245 patients followed for 8-12 years. Acta Orthop Scand 74(2):140

35 Schramm M, Keck F, Hohmann D, et al. (2000) Total hip arthroplasty using an uncemented femoral component with taper design: outcome at 10-year follow468

46936 Engh CA, Massin P (1989) Cementless total hip arthroplasty using the anatomic 470 medullary locking stem. Results using a survivorship analysis. Clin Orthop Relat Res 249:141 
37 de Nies F, Fidler MW (1996) The Harris-Galante cementless femoral component: poor results in 57 hips followed for 3 years. Acta Orthop Scand

38 Hozack W, Gardiner R, Hearn S, et al. (1994) Taperloc femoral component. A 2-6-year study of the first 100 consecutive cases. J Arthroplasty 9(5):489 67(2):122 arthritis. Clin Rheumatol. 27(10):1217

$\underline{\text { Table 1. Reoperation summary of all analysed hips }}$

\section{Components}

revised

4.1

\subsection{0}

10.1

8.8

9.3

12.0

After operation

(years)

Zirconium coated Phoenix cup

Zirconium coated Phoenix cup

Inlay (Aesculap plasmacup)

Zirconium coated Phoenix cup

cemented PE cup

Zirconium coated Phoenix cup

\author{
Revision \\ diagnosis \\ aseptic loosening \\ aseptic loosening \\ extensive inlay wear \\ aseptic loosening \\ aseptic loosening \\ aseptic loosening
}

Table 2. Results in Comparison to the literature of single femoral component series (aRA: adult-onset rheumatoid arthritis; jRA: juvenile rheumatoid arthritis; OA:

Osteoarthritis; n.a.: not available)

\section{Author}

\section{Lachiewicz (1994) ${ }^{\mathrm{a}} \mathrm{jRA}$}

Garcia (1998) $)^{\mathrm{b}}$ aRA

Loehr $(1999)^{\mathrm{c}}$ aRA

Keisu $(2001)^{\mathrm{d}}$ aRA

Jana $(2001)^{\mathrm{e}}$ aRA

Lybaeck (2004) ${ }^{\mathrm{d}}$ jRA

Schramm (2000) $)^{\mathrm{c}}$ OA

Present study ${ }^{\mathrm{c}}$; aRA

${ }^{a}$ Harris-Galante porous (Zimmer)

${ }^{\mathrm{b}} \mathrm{AGB}$ hip prosthesis (Howmedica)

${ }^{\mathrm{c}}$ CLS-stem (Zimmer)

${ }^{\mathrm{d}}$ Taperloc femoral stem (Biomet)

${ }^{\mathrm{e}}$ Anatomic Medullary Locking stem (DePuy, Johnson \& Johnson)

$\begin{array}{llll}\text { No. of } & \text { Mean } & \text { Mean } & \text { Lost to } \\ \text { THA/ } & \text { age at } & \text { follow } & \text { follow } \\ \text { no.of } & \text { operation } & \text {-up } & \text {-up } \\ & \text { patients } & \text { (years) } & \text { (years) }\end{array}$

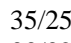

$33 / 32$

$21 / 15$

$50 / 39$

$71 / 55$

$77 / 55$

$89 / 80$

$39 / 27$
4.5

5

3.3

8

11.4

10

10.3

12.2
Excellent Rate of Rate of Rate of Rate of and good stem loosened acetab. loosened

clinical revision stems: revision cups:

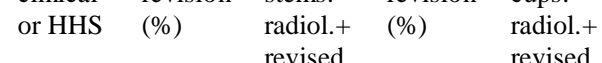

(\%) (\%)

$\begin{array}{llllll}\text { none } & \text { HHS 91 } & \text { none } & \text { none } & \text { none } & 1(3 \%) \\ \text { none } & \text { HHS 81 } & \text { none } & \text { none } & \text { none } & \text { none } \\ \text { none } & \text { n.a. } & \text { none } & 5(24 \%) & \text { none } & \text { none } \\ 19 \% & \text { HHS 93 } & \text { none } & \text { none } & 7(14 \%) & 7(14 \%) \\ 13 \% & \text { n.a. } & 1(2 \%) & 5(7 \%) & 14(20 \%) & 21(30 \%) \\ 9 \% & \text { n.a. } & 2(3 \%) & \text { n.a. } & 27(39 \%) & \text { n.a. } \\ 7 \% & 84 \% & \text { none } & 4(5 \%) & 3(4 \%) & 7(9 \%) \\ 13 \% & \text { HHS } 86 & \text { none } & \text { none } & 6(22 \%) & 6(22 \%)\end{array}$


530

531

532

533

534

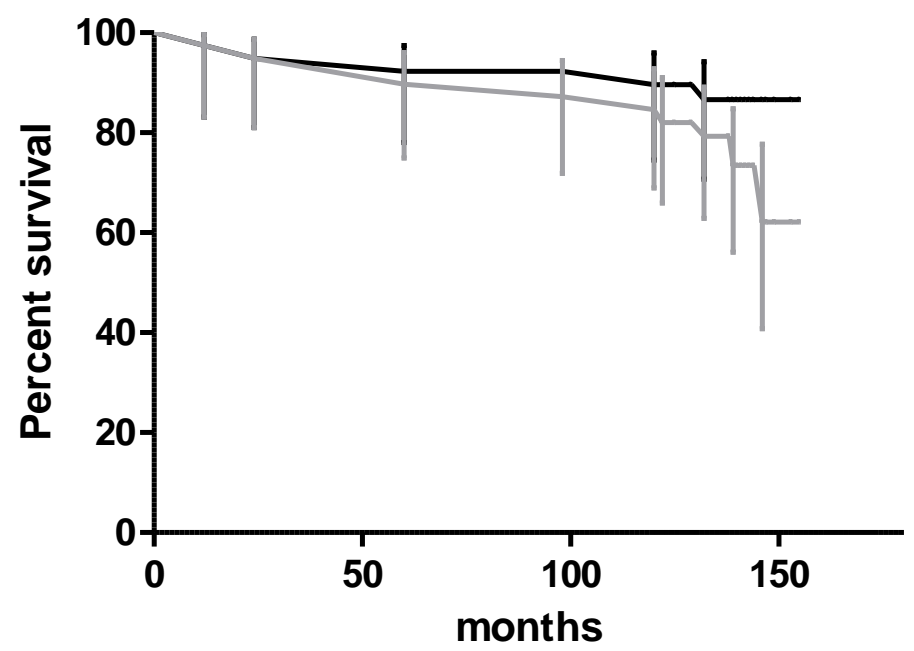

- Lost to FU

- worst case scenario

535

536

537

538

Figure 1 Kaplan Meier curve indicating the lost to follow-up and a worst case (lost

539 to follow-up and deceased patients) scenario.

540

541

542

543

544

545

546

547

548

549

550

551

552

553

554

555

556

557

558

559

560

561 


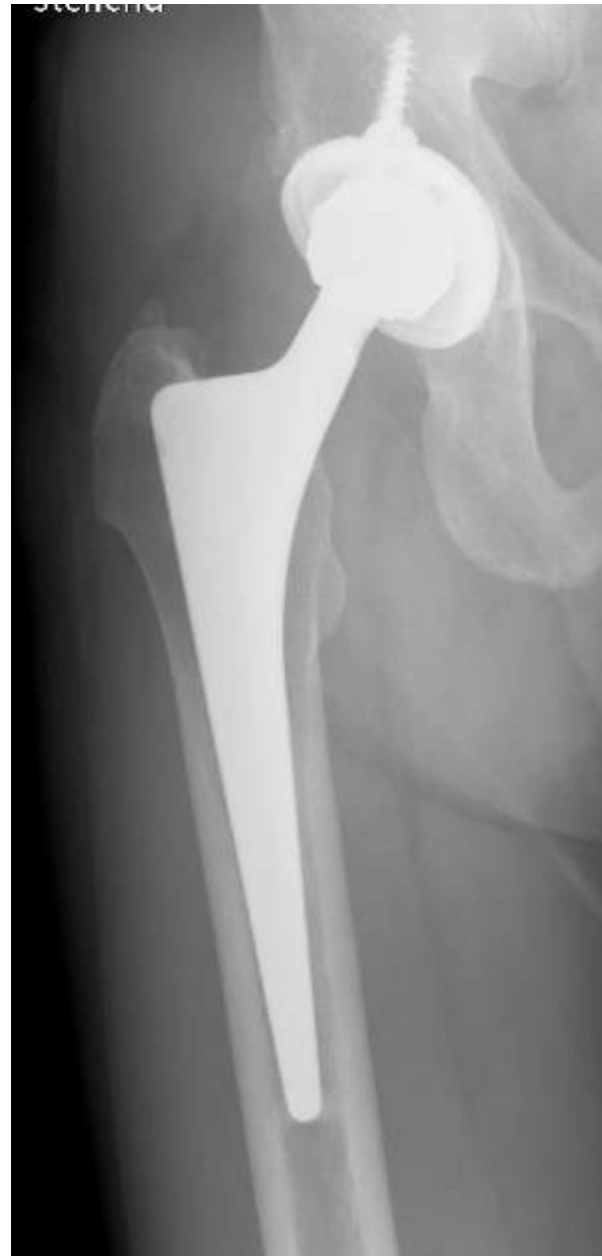

566

567

568

569

Figure 245 year old male, 14 year follow-up. CLS-stem with Fitek press-fit cup. Stress-shielding in Gruen zones I and VII. 